\title{
INDIGNAÇÃO, POLÍTICA E DIREITO EM ESPINOSA ${ }^{1}$
}

Luiz Carlos Montans Braga ${ }^{2}$

\begin{abstract}
Resumo
Espinosa elabora uma filosofia política e jurídica anômala em face de seu tempo e da posteridade. Suas inovações podem ser percebidas desde a importância dada aos afetos na fundação e manutenção do estado até a tese do direito natural definido como potência, à revelia da tradição essencialista, o qual permanece no corpo político após a instituição da cidade. No interior do grande quadro de inovações propostas pelo autor, o objetivo do artigo é fazer a análise de uma pequena seção. $\mathrm{O}$ recorte consiste em compreender a importância e o papel do afeto indignação para a política e o direito na filosofia espinosana. Para isso, o método é o da análise de fontes primárias com eventual auxílio de comentadores. Os resultados da pesquisa indicam que teorias tradicionais do direito, que o apreendem apenas como lei positivada, exterior ao político e ao campo afetivo, podem criminalizar precisamente o que há de mais jurídico, ou seja, o que Espinosa chamaria de direito de guerra em relação a instâncias que oprimem. Indicam, igualmente, que as cidades e suas leis podem ser violentas quando incapazes de compreender que o poder emana da multidão, a qual busca afetos de alegria. O estudo contribui, por meio da análise dos conceitos espinosanos, para alargar o campo de compreensão do direito e da política.
\end{abstract}

Palavras-chave: Indignação; Política; Afetos; Direito como potentia; Espinosa.

\section{INTRODUÇÃO OU A FILOSOFIA POLITICA ANÔMALA DE ESPINOSA}

Espinosa elabora uma filosofia política sui generis, cujas facetas inovadoras são várias: importância dos afetos na fundação e manutenção do imperium ${ }^{3}$; o conceito de paz como fortaleza de ânimo e não como ausência de guerra - o que implica a reelaboração da relação súdito-cidadão versus poder soberano -; a importância da lei segundo a qual entre dois bens se escolhe o maior e entre dois males, o menor, tudo de acordo com o metro afetivo; o desejo como a própria essência do homem; os conceitos de bem e mal são colocados sob o critério do desejo, e não de um metro exterior ao homem; o direito natural é definido como potência, à revelia da tradição essencialista ${ }^{4}$, e permanece no corpo político após a instituição da cidade. Todo esse rol conceitual, apenas

\footnotetext{
${ }^{1}$ Este artigo é versão bastante modificada, com vários adendos temáticos, do item (f) do Capítulo 1 de minha tese de doutorado (MONTANS BRAGA, 2015).

2 Professor do Departamento de Ciências Humanas e Filosofia da UEFS - Universidade Estadual de Feira de Santana. Pós-doutorando em Filosofia pela PUC-SP. Doutor em Filosofia pela PUC-SP. Mestre em Direito pela USP.E-mail: montansbraga@hotmail.com

${ }^{3}$ Imperium é comumente traduzido por estado. Diogo Pires Aurélio, nas traduções abaixo citadas (nota 4), opta por este termo - com $e$ minúsculo. 0 argumento é o de que "tal como acontece no original latino, redige-se "estado" com minúscula, entre outras razões porque o contrário poderia sugerir a plena autonomização do conceito, a qual não se verifica no texto." (ESPINOSA, 2009, nota 4, p. 03).

${ }^{4}$ Tradição essencialista, com diversas facetas na história da filosofia, para a qual a natureza do direito natural seria ou racional ou metafísica (divina, por exemplo). Um exemplar desta tradição está na Antígona, de Sófocles (SÓFOCLES, 1997, p. 62 - numeração universal: 446 e seguintes). 0 conceito
} 
exemplificativo, dá o tom e a magnitude das inovações espinosanas no campo da filosofia política. No interior deste quadro geral, o objetivo do artigo é, em um primeiro momento, fazer a análise de uma pequena seção. O recorte consiste em compreender a importância e o papel do afeto indignação para a política, bem como para o direito, na filosofia espinosana. Assim, serão trabalhadas as questões seguintes: (a) a natureza do afeto indignação, isto é, sua definição; (b) como ele é experienciado pelos homens; (c) por fim, como ele é definidor dos rumos do poder soberano - da relação deste com a multidão - na cidade e dos rumos da cidade, isto é, da permanência desta como corpo político ou sua dissolução. Em um segundo momento, conclusivo, com uso de conceitos de um autor contemporâneo, a saber, Boaventura de Sousa Santos, tais elaborações serão trazidas ao contemporâneo para mostrar como os movimentos de resistência, geograficamente espraiados, podem ser melhor compreendidos pelas lentes espinosanas, especialmente pela interdependência entre o afeto indignação, o direito e a política.

O método empregado é o da pesquisa e análise de fontes primárias, fundamentalmente, com auxílio, eventual, de comentadores. Para a seção final, conclusiva, os conceitos espinosanos são colocados em diálogo com um autor contemporâneo e com temas atuais relacionados ao direito e à política. Os conceitos alargados de direito e de política, propostos por Espinosa, os quais operam em relação com o campo afetivo, possibilitam que se enxergue o que é ocultado ou vedado pelas teorias jurídicas formalistas e legalistas. Tais teorias não serão objeto deste artigo, o qual pressupõe que elas sejam compreendidas como aquelas que focam a lei positivada e temas adjacentes como sinônimo do que seja o direito.

Importa destacar, igualmente, que o foco principal do artigo é mostrar como se articulam os conceitos de indignação, política e direito em Espinosa. A seção que traz tais conceitos ao tempo presente apenas pretende lançar notas que indicam a potência explicativa e inovadora do autor para os temas tratados.

\section{NATUREZA DO AFETO INDIGNAÇÃO}

Espinosa define o afeto indignação como "o Ódio a alguém que fez mal a outro." (E III Def af 20 p. 349)5.

elaborado por Tomás de Aquino na Suma Teológica é outro exemplo - questão 57 da segunda parte da segunda parte - IIa IIae (TOMÁS DE AQUINO, 2016, p. 367 e seguintes). Para o tema da tradição essencialista versus tradição do direito natural como potência, ver: DELEUZE,2009, pp. 86-95. Afirma: "Então, vejam, estou tentando justamente montar um quadro de proposições, [...], e digo simplesmente que, nas proposições da teoria do direito natural clássico, Cícero-São Tomás, vocês têm o desenvolvimento jurídico de uma visão moral do mundo; e no outro caso, a concepção que encontra seu ponto de partida em Hobbes, vocês têm o desenvolvimento e todos os germes de uma concepção jurídica da Ética: os seres se definem por sua potência." (p. 94). Para um estudo do tema da potentia e sua relação com a liberdade política e com o direito, em Espinosa, ver: GOMES, 2017, especialmente capítulo 3 (pp. 51-74).

${ }^{5}$ No intuito de possibilitar o acesso às várias edições da obra de Espinosa, citar-se-á da maneira que segue: quanto à versão original latina (ESPINOSA, 1972 [1aㅡ ed. 1925]), G, romano para o tomo, arábico para a página. As traduções utilizadas são: ESPINOSA, 2003. ESPINOSA, 2008. ESPINOSA, 2009. ESPINOSA, 2014. ESPINOSA, 2015. Para a Ética, E. Parte em romano. D: definições. Def af: definição dos 
No rol das Proposições da mesma parte III, sua definição é a de número 22, em seu escólio. Diz a Proposição 22 que "Se imaginamos que alguém afeta de Alegria a coisa que amamos, seremos afetados de Amor a ele. Se, ao contrário, imaginamos que ele a afeta de Tristeza, inversamente também seremos afetados de Ódio contra ele." (E III P 22 p. 273). Os conceitos movimentados por Espinosa para a compreensão do afeto indignação são imaginação, alegria, amor, tristeza, ódio, e a relação com o outro. A relação com o outro fica clara quando Espinosa apresenta uma triangulação entre dois homens - no mínimo - e uma coisa ou outro homem. Que se analise de perto, em seus elementos constitutivos, a triangulação. Um homem, Pedro, afeta outro, José, de alegria. Este outro é a coisa (ou homem) que é amada, por exemplo, por Maria, Paulo, etc. Por conseguinte, afirma Espinosa, toda Maria, Paulo, etc. serão afetados de amor por aquele primeiro homem Pedro. O inverso vale no que se refere ao afeto tristeza. Caso se imagine que Pedro afeta José de tristeza, sendo José a coisa ou homem que Maria, Paulo, etc. amam, estes serão afetados de ódio em face de Pedro. Esse o mecanismo afetivo para a triangulação entre três homens (ou mais, numa complexificação da relação) e os afetos alegria, tristeza, amor e ódio.

Em suma, "o Ódio a alguém que fez mal a outro" (E III Def af 20 p. 349) é o afeto indignação, e sua estrutura decorre do mecanismo afetivo descrito na Proposição 22 da Ética III. Ocorre que essa relação pode se tornar mais e mais complexa. Basta colocar mais homens num dos polos, experimentando ou vivenciando o mesmo afeto.

Suponha-se que trinta homens amam Pedro. Isto é, pelo mecanismo deste afeto, Pedro provoca em cada um dos trinta homens uma ideia que faz que haja, em cada um deles, aumento da alegria, pois o amor é uma alegria ou amento da potência acompanhada da ideia de uma causa exterior (E, III, Def af 6 p. 343). Neste caso, a causa exterior, em cada um dos trinta homens, é Pedro ou uma ação feita por Pedro. José faz a Pedro algo que para este é um mal. Por conseguinte, os trinta homens odiarão José, isto é, sentirão o afeto indignação em face de José. José pode ser substituído por um conjunto de homens. A lógica afetiva será a mesma, mas neste caso de um conjunto de homens em face de outro.

O mimetismo afetivo terá papel fundamental na disseminação da indignação. A mera semelhança de outro em face daquele que experiencia o afeto é um dos núcleos do mecanismo da imitação, tema que será analisado a seguir.

afetos. A: axiomas. Dem: demonstrações. P: proposições. Cor: corolários. Ap: apêndices. L: lemas. Esc: escólios. Post: postulados. Explic: explicações. Numeral arábico para o número de cada item indicado. Após, a página em arábico - tradução do grupo de Estudos Espinosanos. Quanto ao TP, romano indica o capítulo, arábico o parágrafo, e após a página em arábico da tradução de Diogo Pires Aurélio. Quanto ao TTP, romano indica o capítulo e após a página em arábico da tradução de Diogo Pires Aurélio. Procedese desse modo à revelia das normas da ABNT, mas respeitando seu espírito de possibilitar a melhor forma de acesso aos textos. 


\section{IMITAÇÃO AFETIVA}

De acordo com Macherey, psicossociologia seria o termo usado contemporaneamente ${ }^{6}$ para o que Espinosa apresenta nas Proposições 21 a 34 da parte III da Ética. Nelas, a relação dos homens entre si se apresenta em sua lógica afetiva. E, mais largamente, escreve o autor, referindo-se à parte III da Ética como um todo, a teoria dos afetos embasa a socialidade e a política que daí decorre?

Uma psicossociologia, dir-se-ia hoje, sobre como Espinosa relaciona mente-imaginação, lógica afetiva e construção de relações de vínculo social entre os homens. O que significa este conceito? Significa que os homens como conatus ou, mais especificamente, como seres desejantes, são abertos uns aos outros, assim como ao mundo. São vários Janus que, em vez de bifrontes, têm múltiplas faces, com janelas abertas para o mundo, aí inclusos os outros homens. Este regime de troca afetiva entre homens, esta economia dos afetos ${ }^{8}$, quando se apresenta como mimetismo afetivo ${ }^{9}$, é um dos fundamentos mais relevantes para a política. Analisa-se a seguir os fundamentos da tese espinosana da mimese afetiva.

Seu aspecto central está na Proposição 27 e em seus desdobramentos, isto é, demonstrações, corolários e escólios (E III P 27 pp. 279-281). Estabelece a Proposição 27 que "Por imaginarmos afetada por algum afeto uma coisa semelhante a nós e pela qual jamais nutrimos nenhum afeto, somos então afetados por um afeto semelhante." (E III P 27 p. 279). Espinosa usa a expressão "por imaginarmos". Ou seja, é a potência de imaginar da mente que traz um efeito à mente daquele que imagina. E isto ocorre quando este homem imagina uma coisa semelhante a si afetada de algum afeto. "Uma coisa semelhante a nós" ( quod rem nobis similem - E III P 27 p. 279; G III p. 160): este termo remete a uma capacidade de ser movido pela imagem de algo semelhante a nós imaginar um outro humano afetado de algum afeto. Remete, pois, ao conceito que será trabalhado no escólio da Proposição 50 da Ética IV, a saber, o de desumanização. Neste escólio Espinosa afirma o que segue: "Pois quem

\footnotetext{
${ }^{6} 0$ termo psicossociologia, utilizado por Macherey, é, certamente, anacrônico. Tal expressão não se encontra nos textos de Espinosa, mesmo porque o termo sociologia não havia sido criado no século XVII, pois foi forjado na primeira metade do século XIX por Auguste Comte. É grego, por outro lado, o termo psyche, portanto anterior a Espinosa. Não obstante, a expressão psyche não se encontra nos seus textos. Mantem-se, em alguns momentos do texto, por questões didáticas, o uso do termo psicossociologia, com essas ressalvas. Importa lembrar que Macherey o utiliza fazendo também uma ressalva ("[...] Spinoza se engaja numa empresa do que nós chamaríamos hoje de uma psicossociologia."- tradução minha, p. 188, nota 2). Ver: MACHEREY, 1995, p. 188, nota 2.

7 MACHEREY, 1995, p. 188. Afirma o autor: "Esta temática propriamente política será explicitada na parte seguinte da Ética, e ela será explorada sistematicamente na última obra de Espinosa, o Tratado político: mas seus conceitos de base e suas grandes orientações se encontram já formulados no contexto da teoria dos afetos que constituem a terceira parte da Ética, onde são lançados os fundamentos de uma análise das formas humanas da socialidade”. (p. 188 - Tradução minha).

8 MACHEREY, 1995, p. 189, p. 215. Ver também: CAMPOS, 2008, p. 244.

${ }^{9} 0$ termo é usado como parte do título do capítulo 3 do livro de Macherey (MACHEREY, 1995, pp. 183262, especialmente pp. 214-226).
} 
não é movido pela razão nem pela comiseração a auxiliar os outros, este é corretamente denominado desumano, visto que (pela Prop. 27 da parte 3) parece não ter semelhança com o homem." (E IV P 50 Esc p. 455). Não se desdobrará, neste artigo, o tema da desumanização a partir dos conceitos espinosanos, o que poderia indicar, para análises sobre os tempos atuais a partir dos conceitos espinosanos - eis uma hipótese -, a dissolução da política, um regime fascista, o qual pode inclusive vir travestido do mais pleno estado de direito ${ }^{10}$. No momento, o objeto do artigo demanda apenas a explicação do mecanismo da imitação afetiva, fundado na Proposição 27 da Ética III.

O fundamento da Proposição 27, explicitado na Demonstração seguinte à Proposição, está em teses já expostas por Espinosa nas Proposições 16 e 17, escólio, da parte II da Ética (E II P 16 e P 17 Esc pp. 163-169). Nelas, Espinosa mostrou que as imagens das coisas são afecções do corpo e que as ideias desses corpos exteriores são presentes a cada um. As ideias do corpo exterior envolvem a natureza do corpo exterior e a natureza do próprio corpo, que foi afetado pelo corpo exterior. Sendo a natureza do corpo exterior semelhante à do próprio corpo, "por imaginarmos afetada por algum afeto uma coisa semelhante a nós, seremos afetados junto com ela por um afeto semelhante." (E III P 27 dem p. 279). No escólio seguinte à demonstração, Espinosa usa a expressão imitação dos afetos (affectuum imitatio). E afirma que tal imitação, quando se refere à tristeza, chama-se comiseração ${ }^{11}$. Quando tal imitação se refere ao desejo (cupiditas), chama-se emulação (aemulatio). E este afeto é definido como sendo o desejo de alguma coisa produzido em cada homem por imaginar que os outros, semelhantes, têm esse mesmo desejo. No escólio, por fim, Espinosa afirma que essa vontade (voluntas) ou esse apetite (appetitus) - termos que para Espinosa são sinônimos (E III P 9 esc pp. 253-255) - de fazer o bem que provém da comiseração em face da coisa em relação à qual se quer fazer o bem chama-se benevolência (benevolentia), ou seja, um desejo surgido da comiseração (E III P 27 Esc p. 281). Depois, trata do apreço e da indignação, remetendo ao escólio da Proposição 22 (E III P 22 esc p. 273).

Intenta-se indicar, a seguir, por que há nesta Proposição e em seus desdobramentos (demonstrações, corolários e escólio) tanto uma psicossociologia quanto um apontar para a socialidade e para a política.

Uma psicossociologia pode ser entendida como um jogo de cada psique, de cada mente de cada homem, com a do outro, numa economia de psiques. Isso de tal maneira que se chega a um todo ou alguns todos, os quais se apresentam não mais como individuais no sentido de um homem separado do outro, mas como co-individuais

\footnotetext{
${ }^{10}$ Sobre o tema da desumanização, ver um belo ensaio de Laurent Bove, que traz um diagnóstico sobre o terror ordinário vivido pelas pessoas no mundo contemporâneo: BOVE, 2008, pp. 111-122. Afirma o autor: "O terror não é apenas um simples sentimento de medo, e mesmo de pânico extremo, mas o poder mortal, silencioso e secreto que distancia o coração e o espírito da identificação espontânea à dor do semelhante." (p. 118) (tradução minha). Artigo traduzido em: BOVE, 2010, pp. 89-98.

11 Na tradução de Tomaz Tadeu (ESPINOSA, 2008, p. 195), a expressão usada para o termo commiseratio é comiseração, assim como na tradução do Grupo de Estudos Espinosanos (GEE), ora adotada (ESPINOSA, 2015, p. 279). Na tradução de Roberto Brandão, usa-se compaixão. Ver: ESPINOSA, 2014, p. 49.
} 
ou sociais. Usa-se o termo co-individualpara mostrar que, na imitação dos afetos, o indivíduo continua indivíduo, com sua ratio de movimento e repouso e com suas ideias se encadeando e, simultaneamente, partilhando do outro enquanto ideia-imagem presente em sua mente. Ou seja, cada homem como desejo experimenta o outro no seu corpo como afeto, porém não um afeto qualquer, mas uma imitatio, um caminhar no mesmo sentido do outro.

Como os afetos primários são a alegria e a tristeza enquanto transição [transitio] do desejo de cada homem, quando um homem tem sua potência diminuída porque viu o infortúnio alheio (comiseração), pela lógica dos afetos, o que ocorre é o que segue: este homem é levado com o pathos do outro, ou melhor, é levado pelo pathos que o outro sente. Sentir-com o outro é ter uma presença do outro em si mesmo, como imagem, simultaneamente a um afeto de tristeza, portanto de diminuição da potência do desejo. Entretanto, o que importa para a lógica da imitação é um afeto cuja mecânica é a mesma do afeto do outro, tudo isso produzido pela imagem do outro em mim e que me move no mesmo sentido do outro, provocando em mim, tal qual no outro, um mesmo sentimento de tristeza. Ambos os modos finitos, por imitação, vão num mesmo sentido afetivo. São, afetivamente, comoum.

A mesma lógica vale para a emulação, que nada mais é, escreve Espinosa, do que seguir o desejo do outro, isto é, o que ocorre quando o desejo segue o que o desejo do outro deseja. Como o desejo do outro é o desejo de alguma coisa, quando o desejo de Pedro deseja o mesmo que o de João, o afeto que Pedro experiencia é a emulação (E III P 27 esc p. 279).

Portanto, seja na diminuição da potência, seja em seu aumento, tanto as coisas do mundo podem estar presentes no corpo e mente de um homem, como outros homens podem também estar presentes - como imagens, como afetos.

$\mathrm{Na}$ comiseração, o movimento do afeto em um homem e nos outros é no sentido da tristeza. Na emulação, imita-se o desejo do outro e o impulso do corpo e da mente se dão no mesmo sentido do impulso do outro.

Nesse momento, alguém e outro não mais são apenas mentes isoladas, mas algo em comum os une num sentido. Neste momento o laço social está formado. Por isso se trata, como bem definiu Macherey ${ }^{12}$, de uma psicossociologia fundada na imitação dos afetos. Os laços sociais, os quais fundarão a política, são eminentemente

12 MACHEREY, 1995, pp. 183-262. Como afirmado em nota anterior, Macherey diz que Espinosa faz o que hoje se chamaria de uma psicossociologia. Mantem-se o termo, em alguns momentos do texto, por uma questão didática, em um anacronismo controlado. 
afetivos e, portanto, portadores de potências, de direitos ${ }^{13}$.

O escólio da Proposição ora analisada trata, em seu final, do amor e do ódio em face daquele que "fez bem ou mal a uma coisa que imaginamos semelhante a nós." (E III P 27 Esc final p. 281). Remete, para isso, ao escólio da proposição 22 da mesma parte.

Como analisado, no referido escólio da Proposição 22 Espinosa trata do apreço e da indignação (indignatio). E complementa dizendo que é possível sentir comiseração, apreço ou indignação por uma coisa pela qual não se é tomado, anteriormente, de qualquer afeto, desde que seja julgada semelhante (similem) a outro homem. É o caso que se explica na Proposição 27, acima analisada.

Portanto, o afeto indignação aponta para sua natureza política na medida em que seu mecanismo pode se dar por imitação dos afetos. Assim, quando grande quantidade de homens sente ódio daqueles que compõem o poder soberano, a cidade deve temer sua dissolução. Pelo mesmo mecanismo, mas em uma lógica dada com outro afeto, a emulação fará que a robustez da cidade, por um movimento de emulação de um desejo por muitos que desejam aquilo, possa ser formada e mantida. Por exemplo, com a emulação da esperança, afeto alegre, e da segurança, afeto alegre com mais estabilidade, pois a securitas é a esperança cuja dúvida sobre evento passado ou futuro cessou (E III Def af 12 a 15 pp. 347-349).

Se o desejo a ser emulado gera, pelo mecanismo afetivo da emulação, aumento da potência de cada um que experiencia este afeto, a alegria poderá ser experimentada na cidade. A cidade, entretanto, é uma construção afetiva mais complexa, a qual envolve uma ontologia afetiva em exercício dos seus membros entre si e destes com o poder soberano. Em tal complexidade no exercício afetivo se destacam os afetos medo-esperança, segurança, ambição, entre outros, bem como o conceito de emulação. O direito, como transição de potência, tanto do soberano como de cada súdito-cidadão, também estará presente nessa construção da socialidade e da política ${ }^{14}$. Tratar-se-á, de modo breve, abaixo, de pontes entre os conceitos até aqui trabalhados e a filosofia política espinosana.

\section{PONTES COM A POLITICA}

Não é difícil compreender a razão da importância do afeto indignação para a política. Ou, mais precisamente, ele interessa na medida em que pode apontar para a morte da cidade. Far-se-á, a seguir, uma breve incursão pela política para explicitar uma duplicidade deste afeto em relação ao corpo político. Duplicidade, isto é,

13 Para Espinosa, potentia sive jus (potência equivale a direito - TP II 4 p. 12). No mesmo sentido, ver: BOVE, L, MOREAU, P-F., RAMOND, C., JAQUET, C., 2008, pp. 27-44, especialmente p. 38. Também, com a mesma tese: CHAUI, 2003, pp. 197-264.

${ }^{14}$ Para aprofundamento destes temas, entre outros correlatos, ver: MONTANS BRAGA, 2015. 
seu papel pode ser entendido como uma espécie de critério da qualidade da cidade em face dos seus cidadãossúditos e, simultaneamente, como sendo o da causa da morte da cidade como corpo político.

No Tratado político, Espinosa abre o parágrafo $4^{\circ}$ do capítulo IV perguntando se o poder soberano está adstrito às leis e, consequentemente, se pode pecar. A questão do pecado do poder soberano em Espinosa deve ser entendida à luz do escólio 2 da Proposição 37 da Ética IV (E IV P 37 Esc 2 pp.435-439). Lá Espinosa laiciza totalmente este conceito, ao dizer que pecado e injustiça podem ser considerados sinônimos. E ambos devem ser entendidos como uma violação, pelo súdito, de uma lei da cidade. A questão que abre esta passagem do Tratado político, portanto, é relevante na medida em que mostra que a cidade que não se submete às leis da natureza poderia ser considerada não uma cidade, mas uma quimera (chimaera G III 293). Por consequência, a cidade está, escreve Espinosa, submetida às leis, e não pode pecar. Há um elemento ontológico, de potência, na lei da cidade, e esta natureza ontológica da lei não pode ser desconsiderada.

As leis às quais a cidade está submetida têm relação com as leis da natureza como um todo, portanto. Fazer o que quiser com a mesa, ter direito sobre ela, não é o mesmo que poder fazer que ela "coma erva" (TP IV 4 p. 39), afirma Espinosa. Nesse sentido, o direito da cidade tem sua feição ontológica e sua submissão às leis que operam na substância.

Ora, os homens, como parte da natureza, também não podem ser objeto da violência da cidade. Isto é, o poder soberano não pode desconsiderar a natureza, e não pode desconsiderar a natureza humana, escreve Espinosa. Sobre esse ponto, afirma:

embora digamos que os homens estão sob jurisdição não de si mas da cidade [ homines non sui sed civitatis juris esse G III p. 293], não entendemos que os homens percam a natureza humana e adquiram uma outra, nem que a cidade tenha o direito de fazer com que os homens voem ou, o que é igualmente impossível, que os homens olhem como honroso o que provoca riso ou náusea. (TP IV 4 p. 39).

A seguir Espinosa diz que a cidade, para estar sui juris (sob jurisdição de si própria), tem de preservar as causas do medo e da reverência, pois de outro modo deixa de ser cidade (TP IV 4 p. 39). O medo não poderá ser disseminado no corpo político de modo que anule as potências dos súditos. Para este artigo interessa mostrar como o afeto indignação se insere na discussão propriamente política.

No parágrafo $6^{\circ}$, Espinosa afirma - uma vez estabelecidas as balizas da questão de o poder soberano da cidade, por ser coisa natural, não poder desconsiderar a própria natureza - que as leis pelas quais a multidão (multitudo G III 294) "transfere seu direito para um só conselho ou para um só homem" (TP IV 6 p. 40) devem ser violadas quando à salvação comum interessa violá-las. Entretanto, Espinosa acrescenta uma passagem a este raciocínio que deve ser analisada:

Se, contudo, elas [as leis da cidade, o direito civil] são de natureza tal que não podem ser violadas sem que ao mesmo tempo se debilite a robustez da cidade, isto é, sem que ao mesmo tempo o medo comum da maioria dos cidadãos se converta em indignação [Quod 
si tamen ejus naturae sint, ut violari nequeant, nisi simul civitatis robur debilitetur, hoc est, nisi simul plerorumque civium communis metus in indignationem vertatur G III p. 294], a cidade, por isso mesmo, dissolve-se e cessa o contrato, o qual, por conseguinte, não é defendido pelo direito civil [jure civili] mas pelo direito de guerra [jure belli] (TP IV 6 p. 41).

$\mathrm{O}$ que significa esta densa passagem? Primeiro, Espinosa afirma que as leis da cidade devem ser violadas no caso em que a salvação comum está em jogo. Isto é, quando a cidade não é para cada um dos súditos-cidadãos, não existe para possibilitar o exercício da potência de cada um, mas para levar o conatus de cada um ao entorno de um grau zero, é o caso de violá-las. Mas isso não implica que cada privado possa fazer o que quiser, exercer seu poder como lhe aprouver. Somente quem detém o imperium pode violar as leis (TP IV 6 pp.40-41). Logo depois desse raciocínio segundo o qual quem viola a lei é o soberano vem a passagem acima citada, como contraponto. Não casualmente, a passagem se inicia com "Se, contudo, [...]." (TP IV 6 p. 41). Ou seja, há uma exceção à regra do imperium como intérprete único da situação de violação do contrato para a salvação comum.

Este é o caso, de acordo com o texto citado, em que as leis (ou seja, o direito civil da cidade) são de tal natureza que sua violação gera, ao mesmo tempo, a debilidade da robustez da cidade (civitas robur G III p. 294). Mas como isto ocorre? Ora, Espinosa utiliza a lógica dos afetos para explicar esta situação. De fato, a robustez da cidade abalada é sinônimo, indica o texto pela expressão isto é (hoc est), da situação em que o medo comum da maioria se converte em indignação.

De fato, o que mantém a cidade 'como que sob uma só mente' é um imaginário de medo civil à punição das leis. Medo civil, não medo paralisador da potência. A questão é mais complexa que esta afirmação, mas não será desenvolvida aqui. $\mathrm{O}$ que interessa para este momento é a tese espinosana de que um regime afetivo de, digamos, medo civil, medo da lei ${ }^{15}$, possa se transformar em regime afetivo da indignação.

A indignação, define a Ética III, ponto já analisado acima, é um afeto que pode ser entendido como "o Ódio a alguém que fez mal a outro" (E III Def af 20 p. 349). O medo, como afeto triste, é, paradoxalmente, apropriado pelas instituições da cidade para gerar a segurança como afeto derivado da esperança cuja dúvida cessou. Isto é, a cidade é capaz de fazer da esperança uma segurança por meio de leis que são respeitadas. Cria-se um imaginário comum de futuro seguro, em que leis, que por hábito são cumpridas, continuarão a ser cumpridas. Há um custo, entretanto. O súdito-cidadão tem que temer a punição, sob pena de que a luta entre potências individuais anule as potências individuais elas mesmas e transforme o estado civil em lugar do direito natural como abstração, como opinião (TP II 15 p. 19). É necessário certo grau difuso de medo da lei, ou da punição em caso de violação da lei, o que se poderia chamar de medo cívico, para que o súdito-cidadão possa ter o exercício de sua potência individual em um ambiente de relativa segurança, de equilíbrio do futuro-imaginado-como-presente garantido por instituições.

15 Ver sobre este tema: CHAUI, 2011, pp. 173-191, especialmente p. 184. 
Por que, porém, o medo comum pode vir a ser indignação comum, afeto que rompe a lógica da comunidade ao mesmo tempo em que aponta para o fato de que havia apenas falsa comunidade?

Ora, a chave para se entender este tema espinosano está na passagem citada acima. De fato, o medo comum como medo civil da punição em caso de violação da lei propicia robustez afetiva à cidade. E a cidade detém o imperium, aliás, é o corpo inteiro do imperium (TP III 1 p. 25). E tem a incumbência da república quem, por consenso comum, detém absolutamente o imperium (TP II 17 p. 20). Uma das incumbências de quem detém o poder soberano - incumbência da república - é decretar o conjunto de leis da cidade, interpretar tais leis e aplicá-las. O poder soberano, pois, faz as leis e as aplica. Mas como as leis fundam sua ontologia na potência da multitudo, tema que não será aqui desenvolvido, o conjunto de súditos-cidadãos deve temer as leis civis desde que estas não se apresentem contrárias à natureza humana e à natureza da cidade.

Quando o soberano contraria a natureza (humana ou da cidade), o direito comum que o sustenta por meio do medo às suas decisões se transforma em ódio a alguém que fez mal a outro, ou seja, indignação comum ou indignação da maioria em face do poder soberano.

O poder soberano que edita leis que procuram controlar o que se pensa e o que se diz, cujos membros correm ébrios ou nus com rameiras pelas praças (TP IV 4 p. 39), desrespeitam as leis que eles mesmos ditaram (TP IV 4 p. 39), assassinam súditos, os espoliam, entre outras atitudes que contrariam o motivo pelo qual o poder soberano foi criado, gera nos súditos um afeto que corrompe a cidade: a indignação.

A lógica da indignação está em se odiar quem fez mal a alguém que se ama. No caso da cidade, o medo civil em face das leis por ela editadas é que a sustenta do ponto de vista ontológico. O medo civil, isto é, o medo da punição da lei em caso de violação ${ }^{16}$, é um dos afetos-base da sustentação da cidade como equilíbrio ontológico de forças entre o direito de cada súdito e o direito do soberano. Quando tal medo se transmuta em ódio ao soberano que viola as próprias leis que editou, entre outras ações que levam à dissolução da cidade, o que ocorre é que a potência de quem dá potência ao poder soberano se direciona no sentido de o dissolver. É isso o que Espinosa chama, na passagem citada, de defesa do contrato não pelo direito civil (jure civiliG III p. 294), mas pelo direito de guerra ${ }^{17}$ (jure belli G III p. 294).

Ou seja, quando o poder soberano gera um imaginário afetivo de medo transmutado em indignação, a potência dos súditos não mais se canaliza para dar potência ao soberano e às suas leis, mas para destruí-lo. De fato, neste caso, manter o "contrato" é o direito de guerra em face do "contrato". E o termo contrato, em Espinosa, tem

16 Ver sobre o tema do medo da lei como diferente do medo bruto do estado de natureza: CHAUI, 2011, pp. 173-191, especialmente p. 174

${ }_{17}$ Sobre a prudência como a própria realidade do conatus, o qual pode, em defesa de sua liberdade, exercer um direito de guerra, ver: BOVE, 2002, pp. 09-101, especialmente p. 17. Para o tema da 
sentido diverso de uma comunhão de vontades livres fundadoras de um pacto comum. O sentido parece estar mais próximo de um equilíbrio de forças que gera o poder soberano defensor do comum ${ }^{18}$. Quando o soberano deixa de defender o comum, simultaneamente abre a possibilidade do surgimento do afeto que, difuso, será a causa de sua dissolução. Com efeito, nesta ocasião, apenas o direito de guerra, isto é, a luta contra o poder soberano opressor, restará como ponto de defesa dos direitos naturais dos súditos-cidadãos.

A indignação é, portanto, o afeto que, se sentido pela maioria, põe em xeque a potência do soberano e dissolve a cidade em nome dos direitos naturais de cada súdito-cidadão. E sua face, por conseguinte, é dupla. De um lado, é o afeto que a cidade deve temer (TP III 9 pp. 30-31), pois é o afeto do suicídio da cidade, de sua dissolução. De outro, é sinal de que aquela configuração de poder já não mais atende à razão pela qual foi criada. Daí que o direito civil passe a ser, neste caso, o direito de guerra. Ou seja, o direito de defender o direito natural de cada um quando o poder soberano da cidade já não o faz mais. Ou, por outra, o direito de guerra se apresenta como o poder de retirar do soberano seu poder de dizer o que é a lei e de fazer leis. Neste caso, o direito civil, por ter se desnaturado como tal, se apresenta como direito de guerra. O ponto forte da argumentação espinosana está em que é um afeto, sentido coletivamente e direcionado a quem faz o mal à cidade - o afeto indignação -, o fundamento da dissolução da cidade.

Passa-se, a seguir, a mostrar, muito brevemente, como tais conceitos espinosanos podem ser lentes potentes para analisar o cenário político atual, isto é, os movimentos de resistência aos Estados que impedem que afetos de alegria predominem nas cidades. E, outra face da mesma moeda, o afeto indignação, espraiado por meio da imitação afetiva, formando blocos de indivíduos que manifestam seu direito natural, sua potência, contra as formas de poder soberano que não satisfazem os súditos-cidadãos, mas os violentam ${ }^{19}$.

\section{CONCLUSÃO OU APONTAMENTOS PARA O PRESENTE}

Muitos são os movimentos sociais e políticos, ao redor do mundo - do Brasil à Venezuela, de Portugal e Espanha à Alemanha e França, passando pelos Estados Unidos da América, Turquia, Rússia, etc. -, que podem ser melhor compreendidos pelas lentes espinosanas. As teorias tradicionais do direito (Kelsen e os positivistas de variada estirpe), que o compreendem apenas como lei posta, fora da política e do campo afetivo, tendem a

perspectiva da guerra e uma aproximação com Maquiavel, pp. 31-36. Sobre o tema da resistência, ver: BOVE, 2012, pp. 264-301.

180 tema não será desdobrado aqui, por fugir do recorte proposto. Para o tema, ver: MONTANS BRAGA, 2015, pp. 119-175.

${ }^{19}$ A questão dos Bancos Centrais de diversos países e suas políticas de austeridade é bom exemplo de como o poder soberano pode se distanciar da multidão - que lhe dá poder (TP II 17 p. 20; TP III 2 p. 25) - e criar leis sem potência. Tais leis - em geral decretos, normativas, regulamentos - causam na vol.1 1, no. 02, Rio de Janeiro, 2018. pp. 1037-1051 
criminalizar precisamente o que Espinosa chamaria de direito de guerra em face do poder opressor. Ou seja, pelo mecanismo da imitatio, que deságua nos blocos de indivíduos que agem "como que por uma só mente", instâncias da multidão exercem seu direito natural coletivo como potência coletiva e reivindicam, pela indignação em face de várias ações de alguns Estados, novas institucionalidades, que produzam na cidade afetos de alegria, que viabilizem o aumento dos conatus individuais - os direitos naturais de cada homem - no interior do corpo político.

Nessa chave de crítica às limitações do direito como lei - fora do campo afetivo e político -, e da criminalização dos movimentos reivindicatórios, se posiciona, por exemplo, Boaventura de Sousa Santos, ainda que sem fazer uso das lentes espinosanas, ao apontar que há uma desorganização do direito estatal ao ser obrigado a coexistir com o direito não oficial. $O$ direito não oficial seria, para Boaventura, o dos múltiplos legisladores de fato. Estes, pela força que têm, transmutam o fato e a força em norma. Nesse sentido, competem com o Estado pelo monopólio da violência e criam um direito paralelo (SANTOS, 2003, p. 13). Esse direito paralelo, ainda que nem todo ele, quando direcionado em face do Estado opressor, em forma de movimentos sociais indignados ante atos que diminuem a cidadania, restringindo direitos, é a potência coletiva de que fala Espinosa.

Um breve desvio. São muito bem construídos os argumentos de Boaventura de Sousa Santos para constatar a crise do direito como direito positivado pelo Estado e as exclusões de vastas camadas de pessoas - de uma vida digna, da cidadania, da cultura, etc. - advindas de fascismos como o do capital financeiro (o termo 'fascismo financeiro' é do autor - (SANTOS, 2003, p. 23)). Soam, entretanto, algo ingênuas as constatações do final do referido artigo. Por exemplo, ao afirmar que há o "Estado como movimento social" (SANTOS, 2003, p. 64) quando se constata a prática do orçamento participativo. O exemplo citado pelo autor é o de Porto Alegre. Boaventura afirma ainda que tal experiência estaria se espalhando para as esferas regional e nacional. Não foi, salvo melhor juízo, o que ocorreu - deve-se salientar, entretanto, que o artigo é de 2003. Em suma, discorda-se, pontualmente, aqui, do autor, no que se refere à existência, segundo ele, "hoje em dia, por todo o mundo, [de] um sem número de exemplos concretos de experiências políticas de redistribuição democrática dos recursos resultante da democracia participativa ou de um misto de democracia participativa e representativa" (SANTOS, 2003, p. 66). Constata-se, em vez disso, a existência de movimentos coletivos de revolta ou reivindicatórios que, espinosanamente, poderiam ser chamados de direito natural coletivo em exercício, como acima pontuado. O que é diferente de constatar "exemplos concretos de experiências políticas de redistribuição democrática dos recursos resultante da democracia participativa" (SANTOS, 2003, p. 66). Em uma palavra, concorda-se com o diagnóstico, mas não com todas as projeções que Boaventura faz a partir daí.

Boaventura de Sousa Santos igualmente elabora análises ricas quanto à questão das clivagens presentes

população o afeto indignação em vez de aumentarem a coesão que sustenta o poder soberano. Os exemplos semelhantes são vários e espraiados pelos países. 
nas cidades. Assinala a presença de uma espécie de fascismo social, que se expressa sob algumas formas, como a do fascismo do apartheid social, ou seja, a segregação social dos excluídos por meio da divisão das urbes em zonas civilizadas, de um lado, e zonas selvagens, de outro. As zonas civilizadas (zonas do contrato social, dos castelos neofeudais, dos enclaves fortificados, comunidades muradas, que o Brasil conhece tão bem, especialmente em suas grandes cidades), segundo o autor, veem-se em constante estado de ameaça pelas zonas selvagens, onde o Estado tem dificuldade de impor suas regras. E, no que se refere ao Estado, seu padrão de ação se dá em dois níveis. De um lado, nas zonas civilizadas, atua de forma democrática, comportando-se como Estado protetor, ainda que de forma ineficaz e não totalmente confiável. Nas zonas selvagens, o Estado atua de forma fascista, comportandose como Estado predador, sem qualquer respeito pelo estado de direito. (SANTOS, 2003, p. 21).

Ora, tal corpo político - com um rol de leis e aparatos policiais -, cujo soberano, para governar, se pauta no medo espraiado, medo que se exponencia nas regiões periféricas, onde o Estado, quando chega, o faz como Estado predador, não pode se sustentar por muito tempo com esta formatação.

Os movimentos dos oprimidos - isto é, dos sem educação, dos sem teto, dos sem acesso ao crédito barato e mínimo ${ }^{20}$, à terra, dos sem renda mínima, em suma, aos meios que levam à dignidade material e não material -, organizados pela imitação espelhada do afeto indignação, entre outros mais, quando bem direcionados e organizados em prol de novas institucionalidades, vêm a ser cunha jurídica que coloca em xeque precisamente uma certa formatação do Estado. Isto é, aquela que não é capaz de fazer jus à razão pela qual existe. E qual seria a formatação equívoca? Ora, certamente, para falar com Espinosa, aquela incapaz de garantir um futuro em forma de afeto de alegria (hilaritas), predominantemente, ou seja, um futuro-com-securitas e demais afetos de aumento da potência individual e coletiva.

Pois um Estado, um imperium, incapaz dessa tarefa, é o estado de natureza com outro nome. Daí o direito de guerra, de busca de potência, em forma de reivindicações coletivas, que minam estas institucionalidades que apenas causam tristeza, privação material, medo e, afeto político de dissolução por excelência, a indignação.

Nesse cenário, de jurídico restam as reivindicações coletivas pelo direito à alegria, sob várias formas. E de violento restam as cidades, os Estados e seus poderes soberanos, incapazes de fazer leis com potência, incapazes de compreender, para além da retórica vazia, que o poder emana do povo, ou mais precisamente, da multidão, que luta por afetos alegres, por potência.

INDIGNATION, POLITICS AND RIGHT IN SPINOZA

${ }^{20}$ Não se deve esquecer a prevalência absoluta das finanças (bancos e empresas com atividade semelhante) na governança dos países em tempos atuais. Tais empresas usam, no limite, o argumento da crise sistêmica para serem salvas de bancarrotas geradas também pela falta de regulação por parte 


\begin{abstract}
Spinoza develops an anomalous political and legal philosophy in relation of his time and posterity. His innovations can be perceived by the importance given to the affections in the foundation and maintenance of the state and also by the thesis of the natural right defined as power, against the essentialist tradition. The natural right, according to Spinoza, also remains in the political body after the institution of the city. Inside the great framework of innovations proposed by the author, the purpose of the article is to make the analysis of a small section. The clipping consists in understanding the importance and the role of the affect named indignation for the politics and the right in the spinozian philosophy. For this, the method is the analysis of primary sources with the possible use of commentators. The results of the research indicate that traditional theories about the concept of right, which perceive it only as positive law, external to the political and the affective field, can criminalize precisely what is closest to the concept of right, that is, what Spinoza calls the right of war in relation to oppressors. They also signalize that cities and their laws can be violent when unable to understand that power emanates from the multitude, which seeks affections of joy. The study contributes, through the analysis of the spinozian concepts, to extend the field of understanding the concept of right and the concept of politics.
\end{abstract}

Keywords: Indignation; Policy; Affects; Right as potentia; Spinoza.

\title{
REFERENCIAS
}

AURÉLIO, Diogo Pires. Imaginação e Poder: Estudo sobre a Filosofia Política de Espinosa. Lisboa: edições Colibri, 2000.

BALIBAR, Étienne. Spinoza et la politique. Paris: PUF, 2011.

BOVE, Laurent. Introduction. In: Spinoza. Traité Politique. Trad. d'Émile Saisset. Révisée par Laurent Bove. Int. e notes par Laurent Bove. Paris: Librairie Générale Française, 2002, pp. 09-101.

Vivre contre un mur: diagnostic sur l'état de notre nature en regime de terreur ordinaire. In: Multitudes. 2/2008 (no 33), pp. 111-122. Disponível em: http://www.cairn.info/revue-multitudes-2008-2-page-111.htm. Acesso em 29 JUL 2011 (2008).

Espinosa e a psicologia social: ensaios de ontologia política e antropogênese. (Coleção Invenções Democráticas). Belo Horizonte: Autêntica, 2010.

La stratégie du conatus. Paris: J. Vrin, 2012.

BOVE, L., MOREAU, P-F., RAMOND, C., JAQUET, C. Le Traité politique: une radicalisation conceptuelle? In: La Multitude Libre: Nouvelles Lectures du Traité politique de Spinoza. Paris: ed. Éditions Amsterdan, 2008, pp. 27-44.

CAMPOS, André Santos. Ius sive potentia. Individuação jurídico-política na filosofia de Spinoza. Tese (Doutorado em Filosofia) - Universidade de Lisboa, Lisboa, 2008. Disponível em: http://repositorio.ul.pt/handle/10451/560. Acesso em 05 MAR 2018 (2008).

do Estado. A "mão invisível" do mercado é bastante presente nas casas legislativas e nos poderes executivos, deles extraindo o que é de seu mais estrito interesse, à revelia da sociedade. 
CHAUI, Marilena. Política em Espinosa. São Paulo: Companhia das Letras, 2003. Desejo, paixão e ação na Ética de Espinosa. São Paulo: Cia das Letras, 2011.

DELEUZE, Gilles. Cursos sobre Spinoza (Vincennes, 1978-1981). Seleção e Introdução de E. A. R. Fragoso e H. R. Cardoso Júnior. Tradução E. A. R. Fragoso; F. E. B. de Castro, H. R. C. Júnior, J. A. Aquino. Fortaleza: ed. UECE, 2009.

ESPINOSA. Opera. Ed. de Carl Gebhardt. Heidelberg: Carl Winter, 4 vols, 1972 (1ª ed. 1925).

Ética. Tradução de Tomaz Tadeu. Edição bilíngue (Latim-Português). Belo Horizonte: Autêntica, 2008.

Ética. Tradução incompleta por Roberto Brandão. Disponível em: http://www.andre.brochieri.nom.br/livros/filos/Baruch-Spinoza-Etica-Demonstrada-a-maneira-dosGeometrasPT-BR.pdf. Acesso em 15 ABR 2014.

Ética. Tradução do Grupo de Estudos Espinosanos (FFLCH USP). São Paulo: Edusp, 2015.

Fontes, 2003.

Tratado Teológico-político. Tradução, introdução e notas de Diogo Pires Aurélio. São Paulo: Martins 2009.

Tratado político. Tradução introdução e notas de Diogo Pires Aurélio. São Paulo: Martins Fontes,

GOMES, Carlos Wagner Benevides. Potência e Liberdade na Ética de Benedictus de Spinoza. Dissertação (Mestrado em Filosofia) - Universidade Federal do Ceará, Fortaleza, 2017. Disponível em: http://www.repositorio.ufc.br/handle/riufc/22376. Acesso em 07 MAR 2018 (2017).

JAQUET, Chantal; SÉVÉRAC, Pascal, SUHAMY, Ariel (org.). La Multitude Libre: Nouvelles Lectures du Traité politique de Spinoza. Paris: ed. Éditions Amsterdan, 2008.

KAMINSKY, Gregorio. Spinoza: la politica de las pasiones. Barcelona: Gedisa, 1998.

LAZZERI, Christian. Droit, pouvoir et liberté: Spinoza critique de Hobbes. Paris: PUF, 1998.

MONTANS BRAGA, Luiz Carlos. Trama afetiva da política: uma leitura da filosofia de Espinosa. Tese (Doutorado em Filosofia) - PUC SP, São Paulo, 2015. Disponível em: https://goo.gl/JGmdLQ. Acesso em 08 AGO 2017 (2015).

MACHEREY, Pierre. Introduction à l'Éthique de Spinoza: La troisième partie - La vie affective. Paris: PUF, 1995.

MATHERON, Alexandre. Individu et communauté chez Spinoza. Paris: Les Éditions de Minuit, 1988.

NEGRI, ANTONIO. Espinosa subversivo e outros ensaios. Tradução de Herivelto Pereira de Souza. Seleção de textos, revisão técnica e apresentação de Homero Santiago. São Paulo: ed. Autêntica, 2016.

SANTOS, Boaventura de Sousa. Poderá o direito ser emancipatório? In.: Revista Crítica de Ciências Sociais. n ${ }^{\circ}$ 65. Coimbra: Centro de Estudos Sociais da Universidade de Coimbra, 2003, pp. 03-76. Disponível em: http://rccs.revues.org/1180. Acesso em 12 MAR 2015 (2003).

SÓFOCLES. Três Tragédias Gregas (Antígone, Prometeu Prisioneiro, Ájax). Tradução de Guilherme de Almeida (Antígone). São Paulo: ed. Perspectiva, 1997. 
TOMÁS DE AQUINO. Suma Teológica. Vol 3. Ila Ilae. Tradução de Alexandre Correia. São Paulo: ed. Ecclesiae/Permanência/Cedet, 2016.

Trabalho enviado em 22 de novembro de 2017.

Aceito em 06 de março de 2018. 